\title{
Empowering PowerPoint: Slides and Teaching Effectiveness
}

\author{
Sabra Brock \\ Touro College, \\ New York, NY, USA
}

Sabra.Brock@Touro.edu

\author{
Yogini Joglekar \\ Mountbatten Institute, \\ New York, NY, USA
}

yogini joglekar@yahoo.com

\begin{abstract}
In order to examine the effectiveness of using PowerPoint slides as a teaching aid in the postsecondary classroom, this exploratory study compared the impact on teaching effectiveness of the number and density of slides, as well as the use of visuals and other non-textual elements within slides. The number of slides used per session appeared not to affect effectiveness but lower den sity ( 3 bullet points and 20 words or less per slide) was associated with effectiveness. Results for the 10 instructors teaching 17 classes on information management from 2003 to 2009 were also analyzed by teaching style. Instructors identified as "Experts" and "Facilitators" more often used pictures, photos, charts, graphics, and sound in their slides compared to instructors with other Grasha-Riechman styles. Best practices for using PowerPoint slides are suggested.
\end{abstract}

Keywords: PowerPoint, slides, business education, teaching styles, postsecondary education, presentation skills, multimedia presentations

\section{Introduction}

As entering professionals and organization managers, university graduates will have to be skilled at managing information in their roles to succeed in turbulent economic conditions (Schelee \& Harich, 2010). Postsecondary education in information management has for over a decade included many classes being delivered with PowerPoint and other presentation software as a basis for communication of learning points (Huxham, 2010). Publishers typically supply 20 to 50 slide summaries to accompany each chapter of their textbooks. These slide decks usually have a high degree of production, including animation and links to websites. Students also make class presentations, often relying heavily on PowerPoint slides.

While PowerPoint can be useful in providing a brief outline to facilitate note-taking and underscoring points with "high impact photos, charts, graphs, film clips and humor" its excessive use has been widely considered to be detrimental to the complex decision making required in organi-

Material published as part of this publication, either on-line or in print, is copyrighted by the Informing Science Institute. Permission to make digital or paper copy of part or all of these works for personal or classroom use is granted without fee provided that the copies are not made or distributed for profit or commercial advantage AND that copies 1) bear this notice in full and 2) give the full citation on the first page. It is permissible to abstract these works so long as credit is given. To copy in all other cases or to republish or to post on a server or to redistribute to lists requires specific permission and payment of a fee. Contact Publisher@InformingScience.org to request redistribution permission. zations (Hammes, 2009). The effectiveness of classroom use of PowerPoint slides may be partially determined by instructors' teaching styles. The Grasha \& Riechman teaching styles measurement (Grasha, 1996; Grasha \& Yangarber-Hicks, 2000) could help examine the effectiveness of PowerPoint on teaching information management in the postsecondary classroom. 
The purpose of this study was to examine the possible relationship of the use of PowerPoint slides and teaching effectiveness, in answering the following research questions:

1. What is the relationship, if any, between teaching styles and the use of PowerPoint Slides in information management classes?

2. Does the number of slides used per hour affect teaching effectiveness?

3. Is the density of slides, as measured in numbers of words and bullet points per slide, a contributor to teaching effectiveness?

4. Does the use of drawings, photos, and animations in slides contribute to teaching effectiveness?

5. Is the connection within a slide to a website providing information from the Internet used often and, if so, how does it impact teaching effectiveness?

6. What change has occurred in the use of PowerPoint slides over time in teaching information management?

7. What value do instructors perceive PowerPoint slides add to teaching and learning information management?

Educators may be interested in these findings as they can help set priorities in selecting instructional design elements and provide guidance to students in presenting information. Recommendations are offered to practitioners seeking to support more effective learning of information management in their classrooms.

\section{Theoretical Background}

\section{Literature Review of PowerPoint Use}

Higher education studies on early use of presentation aids primarily focused on the transition from overhead projection to PowerPoint slides as the main presentation medium in classrooms in the 1990s. More recently researchers have mainly examined the linkage between PowerPoint and student engagement (Burke \& James, 2008) or explored the efficacy of this widely used presentation software (Daniels, 1999; Isaacs, 1994). In the past decade, a more nuanced approach to studying PowerPoint usage has emerged, with studies examining aspects such as the connection between PowerPoint handouts and student test or material recall performance (Adams, 2006; Noppe, Achterberg, Duquaine, Huebbe, \& Carol, 2007). A key area that has been explored is the effect of PowerPoint on classroom interactions. Szabo and Hastings (2000) have demonstrated that the use of PowerPoint increased lecture attendance, thereby making the most compelling case for adopting PowerPoint in the classroom. At the same time, Frey and Birnbaum (2002), in surveying a Russian fairytale course, argued that PowerPoint lectures fuelled disruptive behavior in the classroom -- including dozing, checking email, and non-attendance -- as a result of slides being made available outside the class. Burke and James (2008) used the cognitive measure of stimulus novelty to explain the popularity of presentation software in both the academic and realworld business settings. Specifically, they suggest that the perception of novelty through the use of PowerPoint has a positive correlation with constructive classroom attitudes.

Criticisms of PowerPoint have increased in the past decade. Tufte (2003) launched the most vehement critique, arguing that PowerPoint slides lead to over-reliance on a hierarchy of ideas, over-simplification, and linear thinking on part of the presenter and audience. In surveying classes with and without PowerPoint lectures, Cyphert (2004) and Kunkel (2004) discovered that there was no significant difference in student performance or understanding of material. Further, these studies argued that PowerPoint usage stifled pedagogical creativity and led to poorer audience engagement. Neal (1998) argues that technology use in the classroom can actually have a negative impact on teaching and learning by creating impersonality and a shift of focus from a 
"learning experience" to the "delivery of instruction." There is at least one YouTube video pointing out "Death by PowerPoint" (BrainRulesBook, 2008). However, this type of caveat does not appear to be reducing PowerPoint usage in business or even the military (Klein, 2009).

Although the use and abuse of PowerPoint has been explored with relationship to student learning, few studies are currently available that examine the dependency of perceived teaching effectiveness on PowerPoint usage. "Thus far in literature, how the use of... PowerPoint slides affects teaching styles is largely unknown. Do professors speed up their lectures, use more discussion,... put students in a hypnotic state by reading the handouts/slides, or teach in a more relaxed fashion (with PowerPoint)?" (Noppe et al, 2007).

Observation of slide decks provided by publishers of textbooks such as Pearson, McGraw-Hill, and Thompson, as well as feedback from instructors and students in informal sessions led to the hypothesis that PowerPoint slide use varies from class to class and instructor to instructor on the following variables: number of slides per hour/class, word density, layout, use of non-textual elements such as graphics, and insertion of engagement techniques such as questions, assignment set-ups, and web addresses.

\section{Literature Review of Teaching Styles}

Grasha and Riechman's teaching style survey (Grasha \& Riechman, n.d.) outlines a range of teaching roles, namely Expert, Formal authority, Personal model, Facilitator, and Delegator (see Appendix for definitions). Grasha and Yangarber-Hicks' work (2000) takes the concept of teaching styles further and examines their correlation with the use of instructional technology (including audio-visual materials, PowerPoint, and Web content) in the $21^{\text {st }}$-century classroom. Ford and Chen (2001) furthermore posit an interaction between gender, learning styles, and instructional presentation techniques in their work on matching and mismatching learning styles with teaching styles in an introductory HTML course. In another interesting study of teaching styles in business schools, Kragh and Djursaa (2006) examine data from 26 countries to propose a close relationship between indicators of authority and student empowerment. In medicine the use of the Grasha teaching style has been shown to increase teaching effectiveness when used to pair teachers and learners (Vaughn \& Baker, 2008).

However, the teaching styles literature so far has not isolated different kinds of technology and examined them. This paper focuses its attention on one specific (and widely used) presentation software, namely PowerPoint, and limits its examination to the classroom context. Two intersecting axes delineate the scope of this study: (1) Lowman's definition of effective teaching (1994) as a combination of intellectual excitement, interpersonal concern, and motivation, and (2) the instructional method bias (Kragh \& Djursaa, 2006) that credits personal preferences for structural features (visual novelty, in the case of PowerPoint) with selection of teaching processes and methods.

\section{Method}

The authors conducted an exploratory study of faculty members teaching a postsecondary course on information management that was a survey of key topics such as sources, validity, citation style, and use of data in making management decisions. Instructors were asked to indicate the nature of their use of PowerPoint slides, the effectiveness of their use, and to describe their teaching style. In exit interviews, students were asked to evaluate each course module and instructor effectiveness in terms of knowledge of subject matter, professionalism, and understanding.

The Grasha-Riechman instrument was used in classifying instructor style (Grasha \& Riechman, n.d.). Instructors were first asked to identify themselves using the one-word descriptor of the five 
Grasha-Riechman styles and then by a 40 -question inventory included in the web survey. The latter was used in analysis.

The correlation between teaching styles, PowerPoint usage, and perceived teaching effectiveness (through exit interview comments) will be analyzed below. The main focus of investigation is the textual and visual quality of PowerPoint slides used as it relates to teaching styles and studentperceived effectiveness.

\section{Sample and Data Collection}

This study used observation of 17 survey classes (totaling 353 students) on information management conducted in a small post-secondary institute in a major U.S. metropolitan area. These classes were given in the time period 2003 to 2009 by 12 instructors to classes of largely British students. This sample is supplemented by a second program in the same institute involving two classes given to 11 students at the MBA level. Both programs are characterized as having all students work at a full-time internship positions with classes held evenings and weekends.

Because the courses were taught in the U.S., instructors were American and/or drawn from American work backgrounds. Instructor data was collected through a web survey asking the extent and type of use of PowerPoint slides in their classes. The survey was sent in November-December 2009. Ten of the 12 instructors responded for an $83.3 \%$ completion rate.

Learning outcomes were collected via individual interviews immediately on each student's finishing the class over the time period of 2003 to 2009. Students were largely drawn from the United Kingdom (91.2\% British) and were traditional college age. Females represented $54.8 \%$ of the total sample. Prior majors included business $(48.0 \%)$, humanities $(33.1 \%)$, law $(11.4 \%)$, and other (7.5\%). A total of 144 students completed the interview for a $40.7 \%$ completion rate.

\section{Findings}

The average number of slides used per 90-minute session was 22.7 with an average of 27.8 words per slide, divided over 5.6 bullet points. The instructors reported changing slides over time, most by adding graphics elements such as pictures. Some also included web addresses, charts, sound, animations, discussion questions, and exercises. Statistical testing was used to measure differences in instructor use of PowerPoint and its relationship to teaching style. Chi-square tests were used to assess significance. (See Table 1.)

Table 1: Relationship of teaching style and PowerPoint slide elements used"

\begin{tabular}{|l|c|c|c|c|c|}
\hline & $\begin{array}{c}\text { Pictures, photos, } \\
\text { charts, graphics, } \\
\text { sound \& animation }\end{array}$ & $\begin{array}{c}\text { Pictures, photos, } \\
\text { charts \& sound } \\
\text { STYLE }\end{array}$ & $\begin{array}{c}\text { Pictures, photos \& } \\
\text { sound }\end{array}$ & $\begin{array}{c}\text { Pictures \& } \\
\text { photos }\end{array}$ & Text only \\
\hline Expert & $\mathbf{n}=\mathbf{n}$ & $\mathbf{n}=\mathbf{2}$ & $\mathbf{n}=\mathbf{1}$ \\
\hline Formal authority & 2 & 1 & 1 & 2 & \\
\hline Personal model & & & & & \\
\hline Facilitator & 3 & & & & 1 \\
\hline Delegator & & & & \\
\hline
\end{tabular}

"Chi-square testing shows difference at $<.10$ level 
Patterns did emerge in answer to the first research question, What is the relationship, if any, between teaching styles and the use of PowerPoint Slides in information management classes? Instructors identified as having Expert and Facilitator styles reported using more non-textual elements of all types in PowerPoint slides than those with other styles $(\mathrm{p}=<.10)$.

The next three research questions were:

- Does the number of slides used per hour affect teaching effectiveness?

- Is the density of slides, as measured in numbers of words and bullet points per slide, a contributor to teaching effectiveness?

- Does the use of drawings, photos, and animations in slides contribute to teaching effectiveness?

The number of slides used did not affect reported teaching effectiveness, but lower textual density appears to relate to more positive student feedback. The instructor with the highest teaching effectiveness comments and the one with the most negative both used a relatively high number of slides (35) per session. However, the higher rated instructor used only an average of 3 bullets and 20 words per slide, whereas the lower rated instructors used 5-7 bullets and 25-70 words per slide. Both used many forms of graphic additions (pictures, photos, charts, sound, graphics, and illustrations).

Twenty-one of the 353 (5.7\%) students from the 17 information management class sections offered specific comments on PowerPoint slides in their exit interviews, which were conducted by the institution as an additional quality assurance measure along with course evaluations. Positive student feedback on slides from exit interviews, amounting to $3.7 \%$ of the student feedback, was the slides were "nice" and "interesting." The negative comments $(2.0 \%$ of the student feedback) at the other end included: "PowerPoints in advance would be useful" and "could have more discussion with slides."

The instructor feedback was a counterpoint to these student comments. They said the value of PowerPoint slides included an increase in learning when visual elements were used, specifically concise illustrative points and visualized structure. Another theme was the usefulness of copies of slides in distributing notes, especially those with links. More than half the instructors said they watched student engagement with slides and took action when energy dropped: adding team or individual exercises, posting questions and discussion topic slides, and even skipping over less relevant slides to reduce the number.

The fifth research question was, Is the connection within a slide to a website providing information from the Internet used often and if so, how does it affect teaching effectiveness? The highest rated instructor was one of the few not using website addresses on PowerPoint slides, whereas the lowest indicated use of website addresses. In answer to the sixth research question, What change has occurred in the use of PowerPoint slides over time in teaching information management? instructors reported that their slides had changed in character more than in number. Note that this response is likely subject to their ability to recall changes over the six years of the survey period. (See Figure 1.) 


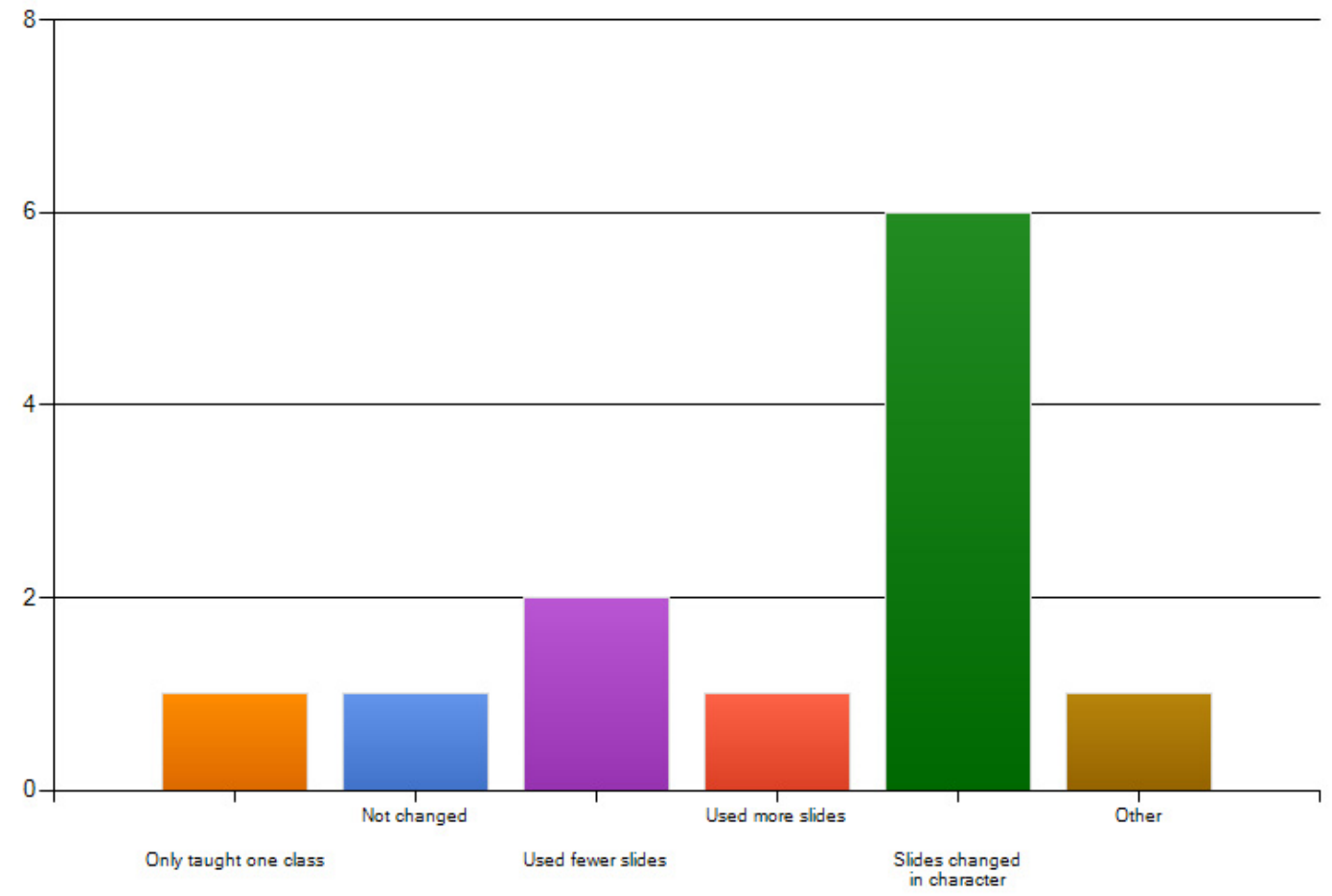

Figure 1. Change in How Slides Used

The last research question was, What value do instructors perceive PowerPoint slides adding to teaching and learning information management? All respondents agreed that PowerPoint slides add visual interest and increase knowledge transfer through visual learning. As one instructor said, "A picture is worth a thousand words." Most also agreed that they help pacing (8 respondents), help organize thoughts, and are a memory aid for presenting ( 7 respondents each). PowerPoint slides are both a memory aid for students and help convey complex ideas compactly (7 respondents). Of less importance were the access to pre-prepared slides (3) and providing students with expected notes (3 respondents).

\section{Conclusion}

This study's outcomes suggest that the use of presentation software such as PowerPoint varies depending on instructors' teaching styles. The connection between the number of PowerPoint slides used in class and perceived teaching effectiveness is not shown to be very robust, rather the character and use of slides is the main focus in student feedback. The suggested rule of thumb is no more than three bullet points or 20 words per slide. Developing more visual slides is important as is using PowerPoint to structure argument and to develop concepts that cannot be easily captured in words.

Instructors with "Expert" and "Facilitator" styles in Grasha-Riechman's model are most likely to use a broad range of visuals to supplement textual slides compared to instructors with other styles. This finding would support the variation in use of audiovisual aids in research on GrashaRiechman teaching styles. 
The study reveals that lower textual density in slides and added non-textual elements both appear to stimulate positive student feedback. This finding may be helpful in understanding of why PowerPoint slides can sometimes increase student engagement and other times reduce it. Slides that are very text dense may not add to teaching effectiveness. And, there was no specific mention of visual novelty as important to engagement, as observed by Burke \& James in 2008. PowerPoint after all is no longer novel.

The strong positive association around the visual quality of PowerPoint slides supports the reported change in slide character being a move away from text-heavy slides. Interestingly, the addition of Website links yielded no report of increased engagement or teaching effectiveness.

Instructors appear to be using PowerPoint slides to communicate learning points and to provide pacing for classroom time. They recognize that visual learning can supplement the spoken word and improve student retention. Dense information and complex ideas can often be better communicated with presentation software, while modeling presentation best practices in class and in the workplace. Effective instructors monitor engagement in their classes and use slides to stimulate discussion. When engagement falters they are prepared to reduce the number of slides used. In sum, the popularity of PowerPoint slides in teaching information management may well increase teaching effectiveness and slides are not used solely due to their availability from publishers.

\section{Delimitations and Limitations}

This survey is limited to students in one business institute in a major Northeastern city in the United States. The school draws students largely from the United Kingdom. Therefore, the results may be generalized only to similar contexts. The longitudinal aspect of this study is based on successive classes of similar students and not on following the same students through a succession of school years.

Other questions must be posed in interpreting this research. Grasha-Riechman's learning styles inventory, which complements their research on teaching styles, has not been considered in this study. In particular the learning preferences of visual learners around PowerPoint slides may have implications that are not explored here.

\section{Recommendations to Practitioners}

The way PowerPoint decks are used appears to be more important to student learning than the number of slides used. The range of the number of slides used (one to more than 30 per hour) suggests that as many as one slide every two minutes can be part of an effective teaching technique. However, best practices dictate that instructors (1) use no more than three bullets points or 20 words per slide; (2) add visual elements to text slides; (3) include devises such as questions and discussion topics in slides; and (4) when student engagement declines, cut out non-essential slides. These guidelines may be useful for not only instructor presentation of information but also for students learning the most effective methods of presenting information.

\section{Recommendations for Future Research}

First, this study was exploratory and the sample sizes are small. Repetition using larger sample sizes is an obvious next step. There is also the likelihood that expectations for classroom formats vary across cultures. Even in this small-scale study, there was some indication that the largely British students expected the American instructors to provide engagement beyond the slides as they had experienced in home-country schools. Thus, research across cultures could expand the implications of the findings. It also may be that PowerPoint slides are more appropriate for survey courses as opposed to specialized courses. The courses used in this study were of the survey 
type and covered key information management topics but made little or no attempt to provide indepth instruction on any one topic. Future research could also include how PowerPoint affects groups such as male/female, high ability/low ability, and different age groups other than the traditional college student.

Furthermore as the media landscape evolves with more animation, videos, and interactive elements on the web, PowerPoint itself will no longer be novel. Therefore, continued current research on its effectiveness is important to gauging how best to use it and new generations of presentation software such as Prezi.

\section{References}

Adams, C. (2006). PowerPoint, habits of mind, and classroom culture. Journal of Curriculum Studies, 38, $389-411$.

BrainRulesBook. (2008, March 6). Death by PowerPoint. Retrieved November 15, 2010, from http://www.youtube.com/watch?v=FJ5dbUCu2Ug

Burke, L. A., \& James, K. E. (2008). PowerPoint-based lectures in business education: An empirical investigation of student-perceived novelty and effectiveness. Business Communication Quarterly, 71, 278296.

Cyphert, D. (2004). The problem of Powerpoint: Visual aid or visual rhetoric? Business Communication Quarterly, 67, 80-84.

Daniels, L. (1999). Introducing technology in the classroom: PowerPoint as a first step. Journal of Computing in Higher Education, 10, 42-56.

Ford, N., \& Chen, S. (2001). Matching/mismatching revisited: An empirical study of learning and teaching styles. British Journal of Educational Technology, 32(1), 5-22.

Frey, B., \& Birnbaum, P. (2002). Learners' perceptions on the use of PowerPoint in lectures. Computers and Education, 41, 72-86.

Grasha, A. (1996). Teaching with style: Enhancing learning by understanding teaching and learning styles. Pittsburgh, PA: Alliance Publishers.

Grasha, A., \& Riechman, S. (n.d.). Teaching style survey. Retrieved November 7, 2010, from www.longleaf.net/teachingstyle.html

Grasha, A., \& Yangarber-Hicks, N. (2000). Integrating teaching styles and learning styles with instructional technology. College Teaching, 48(1), 2-10.

Hammes, T. H. (2009). Essay: Dumb-dumb bulleters. Armed Forces Journal.

Huxham, M. (2010). The medium makes the message: Effects of cues on students' lecture notes. Learning in Higher Education, 11(3), 179-188.

Isaacs, G. (1994). Lecturing practices and note-taking purposes. Studies in Higher Education, 19, 203-217.

Klein, J. (2009, December 28). General Stanley McChrystal. Time, 174(25), 86-93.

Kragh, S. U., \& Djursaa, M. (2006). Modernization and management: Business school teaching across countries. International Journal of Cross Cultural Management, 6(1), 19-36.

Kunkel, K. (2004). A research note assessing the benefit of PowerPoint software in different lecture courses. Teaching Sociology, 32, 188-196.

Lowman, J. (1994). Professors as performers and motivators. College Teaching, 42, 137-141.

Neal, E. (1998, June 19). Using technology in teaching: We need to exercise healthy skepticism. The Chronicle of Higher Education. 
Noppe, I., Achterberg, J., Duquaine, L., Huebbe, M., \& Carol, W. (2007). Powerpoint handouts and college student learning outcomes. International Journal for the Scholarship of Teaching and Learning, 48(1), $2-10$.

Schelee, R. P., \& Harich, K. R. (2010). Knowledge and skill requirements for marketing jobs in the 21 st century. Journal of Marketing Education, 32(3), 341-352.

Szabo, A., \& Hastings, N. (2000). Using IT in the undergraduate classroom: Should we replace the blackboard with PowerPoint? Computers and Education, 35, 175-187.

Tufte, E. (2003). PowerPoint is evil. Retrieved November 7, 2010, from Wired: http://www.wired.com/wired/archive/11.09/ppt2.html

Vaughn, L. M., \& Baker, R. C. (2008). Do different pairings of teaching styles and learning styles make a difference? Teaching and Learning in Medicine, 20 3), 239-247.

\section{Appendix}

GRASHA-RIECHMAN'S TEACHING STYLE DEFINITIONS

(Grasha \& Riechman, Teaching style survey at www.longleaf.net/teachingstyle.html)

Expert Possesses knowledge and expertise that students need. Strives to maintain status as an expert among students by displaying students-knowledge and by challenging students to enhance their competence. Concerned with transmitting information and insuring that students are well prepared.

Formal authority Possesses status among students because of knowledge and role as a faculty member. Concerned with providing positive and negative feedback, establishing learning goals, expectations, and rules of conduct for students. Concerned with the correct, acceptable, and standard ways to do things and with providing students with the structure they need to learn.

Personal model Believes in 'teaching by personal example' and establishes a prototype for how to think and behave. Oversees, guides, and direct by showing how to do things and encouraging students to observe and them to emulate the instructor's approach.

Facilitator

Emphasizes the personal nature of teacher-student interactions. Guides and directs students by encouraging cooperative as well as independent learning activities. Good at questions, exploring options, suggesting alternatives, and encouraging students to make informed choices. Overall goal is to develop in students the capacity for independent action, initiative, and responsibility. Works with students on projects in a consultative fashion and tries to provide as much direction, support, and encouragement as possible.

Delegator

Concerned with developing students' capacity to function in an autonomous fashion. Interested in having people become self-directed, self-initiating learners. Students work independently on projects or as part of autonomous teams. The teacher is available at the request of students as a consultant and resource person." 


\section{Biographies}

The authors wish to acknowledge tabulation assistance from Alex Foard of the Mountbatten Institute.

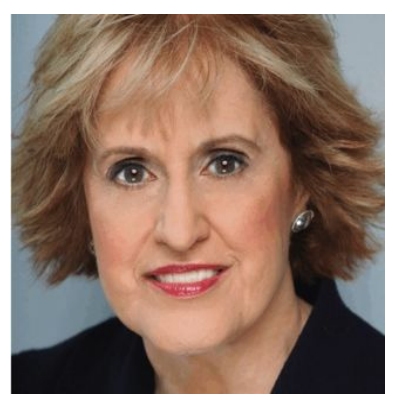

Sabra Brock is an assistant professor at Touro College in New York City where she teaches marketing and management courses to undergraduate and graduate students. She received her doctorate from New York University. Her research interests include collaborative learning in business schools and the workplace, cross cultural teaching, and managing change through transformative learning.

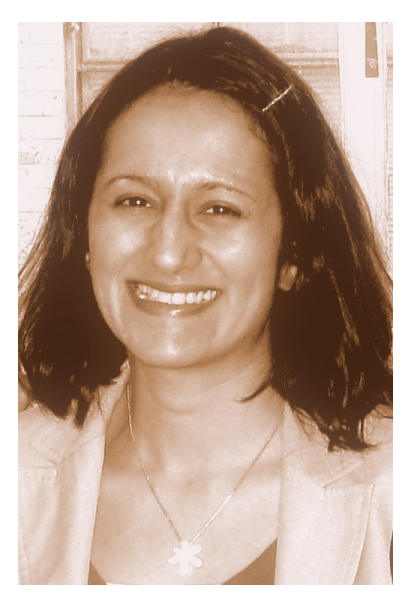

Yogini Joglekar is the founder of Languagability Consulting, a crosscultural consulting and translation firm servicing educational institutions and corporations. Until 2010, she was Academic Director of the Mountbatten Institute in New York, a postgraduate exchange program she managed in collaboration with the University of Cambridge, U.K., and two other academic partners. Her current research projects include international education and $21^{\text {st }}$ century Bollywood cinema 